IV. Aus dem städt. Krankenhause in Hirschberg i. Schl. (Dirigirender Arzt: Dr. G. Middeldorpf.)

\section{Die Verwendung des Wasserstoffsuperoxyds in der Wundbehandlung.}

\section{Von Dr. Oskar Müller, Assistenzarzt.}

In Tillmann's Lehrbuch der allgemeinen Chirurgie findet sich über die Verwendung des Wasserstoffsuperoxyds der kurze Vermerk, dass nach L. v. Dittel dasselbe seines hohen Preises und seiner leichten Zersetzlichkeit wegen als Antisepticum nicht geeignet sei - das Todesurtheil über ein Desinficienz von hohem Werthe und Eigenschaften, die von keinem der anderen Antiseptica erreicht werden.

Die antiseptische Kraft des Wasserstoffsuperoxyds ist seit langem bekannt. Nach Thiriar ${ }^{1}$ ) wurde es bereits vor 20 Jahren von Péan als Antisepticum angewendet, Sinéty empfiehlt es Anfangs der achtziger Jahre gegen die Blennorrhagie der Scheide, 1883 heben Baldy und Carriné seine Vorzüge hervor, 1898 wird es von Lucas-Championnière, 1899 von Dezanneau und Brocis Nenoff empfohlen. Lebesque hat damit Septhämie mit Gasentwickelung geheilt, und Thiriar selbst, der es bei zwei Fällen von Septhämie als einziges bis jetzt bekanntes erfolgreiches Mittel beschreibt, bezeichnet das Wasserstoffsuperoxyd als hervorragendes Antisepticum und Desinficienz, das er bei allen eitrigen Erkrankungen (Tetanus, Pustula maligna, Erysipel, Tuberkulose, Peritonitis tuberculosa mit Laparotomie, Aktinomykose, Panaritiım, Phlegmone, komplizirten Fracturen, Puerperalfieber u. a.) erprobt und bewährt gefunden hat. Ebenso empfiehlt Tissot ${ }^{2}$ ) neuerdings aufs wärmste die Einführung des Wasserstoffsuperoxyds in die Chirurgie als eines ausgezeichneten Desinficienz, besonders für die Behandlung eiternder Wunden.

In Deutschland findet das Wasserstoffsuperoxyd therapeutisch zur Zeit nur in der Zahnheilkunde und Oto-Rhinologie eine beschränkte Anwendung, während es die Industrie zu ihren unentbehrlichsten Chemikalien rechnet. Im Zusammenhange damit steht wohl, dass man es jetzt haltbarer und billiger darzustellen gelernt hat als früher: der Engrospreis stellt sich für 1 Kilogramm auf 0,78-0,80 M. ${ }^{3}$ ), ein Preis, der z. B. im Vergleich zum Alkohol - ich habe dabei die ähnliche Verwendung des Alkohols in Form der Alkoholverbände im Auge - relativ niedrig zu nennen ist. Erst in neuester Zeit hat v. Bruns ${ }^{4}$ ) die Aufmerksamkeit auf die Verwendung des $\mathrm{H}_{2} \mathrm{O}_{2}$ in der Wundbehandlung gelenkt; er empfiehlt es in 1\% iger Lösung bei 'inficirten Wunden und jauchigen Prozessen, Das gleiche geschieht durch B. Honsell5) in einer Arbeit, die ebenfalls aus der Tübinger Klinik stammt.

Bezüglich der Haltbarkeit des Wasserstoffsuperoxyds ist $\mathrm{zu}$ erwähnen, dass es sich bei gutem Verschluss und lichtgeschützt verwahrt (dunkle Flasche), monatelang hält, ohne von seinen Eigenschaften zu verlieren. Allerdings rathe ich - um unliebsame Resultate zu vermeiden --, vor beginnender Einführung des Wasserstoffsuperoxyds mit dem betreffenden Apotheker Rücksprache zu nehmen, da der in dem Apothekenbestande vorhandene Vorrath in Folge des jahrelangen Lagerns den Anforderungen nicht mehr ganz entspricht, oder aber es direkt von chemischen Fabriken zu beziehen. Das für den medicinischen Gebrauch

1) Bull. de l'Acad. roy. de méd. de Belgique 1899, No. X.

2) Gazette des hôpitaux 1899, No. 101.

3) Nach Mittheilung von Gehe \& Co., Dresden-N.

4) Berliner klinische Wochenschrift 1900, No. 19.

5) Beiträge zur klinischen Chirurgie Bd. XXVII, Heft 1. bestimmte Wasserstoffsuperoxyd kommt in $3 \%$ iger Lösung ( 1 Gewichtsprocent $=3,33$ Volumenprocent) in den Handel. Nach v. Bruns stellt Merck es jetzt in hoher Concentration her, so dass dadurch einegrössere Bequemlichkeit und Billigkeit erreicht wäre.

Um die antibacteriellen Eigenschaften des Wasserstoffsuperoxyds festzustellen, habe ich verschiedene Versuche angestellt:

I. a) Sterile Seidenfäden wurden durch einen Furunkel gezogen, getrocknet und in Wasserstoffsuperoxyd eingelegt. Demselben zu verschiedenen Zeiten entnommen und in Nährgelatine verbracht, konnte bereits nach zweiminutlicher Einwirkung des Wasserstoffsuperoxyds ein Wachsthum nicht mehr erzielt werden. Während der Controllseidenfaden unzählige Colonieen aufgehen liess, konnten an dem Seidenfaden. der eine Minute in Wasserstoffsuperoxyd gelegen hatte, nur mehr fünf Colonieen des Staphylococcus pyogenes aureus nachgewiesen werden.

b) Derselbe Versuch wird mit Staphylococcus pyogenes albus vorgenommen, der aus einer Vereiterung des Rückenmarkskanales gezüchtet war und gutes Wachsthum zeigte. Hier konnte bereits nach einer Einwirkung von einer Minute ein Wachsthum nicht mehr erzielt werden.

II. a) Von dem oben erwähnten Staphylococcus pyogenes aureusStamm wird auf Agarröhrchen überimpft, und die Impffläche unter $\mathrm{H}_{2} \mathrm{O}_{2}$ gesetzt, das nach verschieden langer Einwirkungsdauer dann wieder abgegossen wird. Bei einer Einwirkungsdauer des $\mathrm{H}_{2} \mathrm{O}_{2}$ von einer Minute bleibt das betreffende Röhrchen steril, bei 10, bezïglich 30 Sekunden entwickelt sich ein mässiges Wachsthum.

b) Derselbe Versuch mit Staphylococcus pyogenes albus. Alle Röhrchen bleiben steril. Die Controllröhrchen ergeben die typischen Stammculturen.

III. Flüssige Nährgelatine wird mit $1 / 4$ Volumen Wasserstoffsuperoxyd vermischt und mit Staphylococcus pyogenes albus inficirt. Das Röhrchen ist am fünften Tage noch steril. Auch eine erneute Impfung desselben Röhrchens am zehnten Tage lässt kein Wachsthum aufgehen. Nach weiteren fünf Tagen ergiebt eine nochmalige Inficirung dasselbe negative Resultat.

IV. Eine Agarreincultur des Staphylococcus pyogenes albus wird nach zweiminutlicher Einwirkung des $\mathrm{H}_{2} \mathrm{O}_{2}$ vernichtet. Ein Wachsthum lässt sich aus der so vorbehandelten Cultur nicht mehr erreichen. Ebenso wird eine Mischcultur dieses Staphylococcus mit einem nicht näher bestimmten Stäbchen (Wurzelbacillus?) in zwei Minuten abgetödtet.

V. Streptococcus pyogenes, von einer tödtlich verlaufenden Phlegmone stammend, ist in Wasserstoffsuperoxyd-Aufschwemmung nach $1 \frac{1}{2}-2$ Minuten abgetödtet. Eine weitere Ueberimpfung gelingt nicht mehr. Das Controllröhrchen zeigt typisches Verhalten.

VI. Milzbrandbacillen, die sich als stark sporenhaltig erwiesen und mir als eine sehr widerstandsfähige Cultur vom Breslauer hygienischen Institut zur Verfügung gestellt waren, wurden nach 40 Minuten abgetödtet. $\mathrm{Zu}$ diesem Versuche wurde eine Aufschwemmung einer Oese Milzbrandreincultur in $\mathrm{H}_{2} \mathrm{O}_{2}$ benutzt. Nach fünfminutlicher Einwirkung des $\mathrm{H}_{2} \mathrm{O}_{2}$ auf den Bacillus zeigt die jetzt abgeimpfte Gelatinestichcultur zahlreiche Colonieen, die nach 10 Minuten angelegte zweite Abimpfung eine etwas geringere Anzahl. Nach 20 Minuten Einwirkung lassen sich nur noch 15 Colonieen zählen, nach 30 Minuten eine Colonie, ebenso nach 35 Minuten. Nach 40 Minuten bleibt das Röhrchen steril, ebenso nach 45 Minuten. Die Abimpfungen werden bis zur Dauer von 12 Stunden von da ab fortgesetzt - immer mit dem gleichen negativen Resultat. Zum Vergleich wurde in derselben Weise von einer Aufschwemmung des Milzbrandbacillus in einer $1 \%$ Sublimatlösung eine Impfreihe angelegt. Nach 5 Minuten, als die Abimpfungen parallel zur $\mathrm{H}_{2} \mathrm{O}_{2}$-Reihe begannen, war die Cultur abgetödtet. Die Controllröhrchen, die von einer Aufschwemmung in sterilem Wasser angelegt wurden, zeigten typisches Verhalten.

Honsell sagt in der oben angeführten Arbeit, dass das $3 \%$ ige Wasserstoffsuperoxyd dem $1 \%$ Sublimat in wässerigen Lösungen gleichzustellen sei. Ich kann mich dem nach dem bacteriologischen Versuche nicht anschliessen. Vielmehr ist dem $\mathrm{H}_{2} \mathrm{O}_{2}$ gegenüber dem $1 \%$ Sublimat eine weit geringere antibacterielle Kraft eigen, besonders den widerstandsfähigen Sporen gegenüber.

Tabelle der bacteriologischen Versuche.

\begin{tabular}{|c|c|c|c|c|c|c|c|c|c|c|c|c|c|}
\hline \multirow{2}{*}{ Einwirkung des $\mathrm{H}_{2} \mathrm{O}_{2}$ auf } & \multicolumn{12}{|c|}{ Zeit der Einwirkung in Minuten } & \multirow{2}{*}{ Controllröhren } \\
\hline & 0,2 & 0,5 & 1 & 2 & 5 & 10 & 20 & 30 & 35 & 40 & 45 & 50 & \\
\hline Ia. Staph. pyog. aur. auf Seidenfäden & . & $\cdot$ & + & - & - & - & . & & . & . & & . & + unzählig \\
\hline b. Staph. pyog. alb. auf Seidenfäden & . &. & - & - & - & - & & . & . & . & & & + viel \\
\hline $\begin{array}{l}\text { IIa. mit Staph. pyog. aur. beschickte } \\
\text { Agarrohrchen }\end{array}$ & + & + & - & - & - & & . & . & & 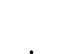 & & & + typ. Wachsthum \\
\hline b. mit Staph pyog. alb. beschickte & - & $\overline{-}$ & 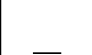 & - & 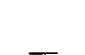 & & & & & & & & (5) \\
\hline $\begin{array}{l}\text { Agarröhrehen } \\
\text { IVa. Agarreincultur d. Staph. pyog. alb. }\end{array}$ & . & . & . & - & . & : & . & . & : & $\dot{ }$ & . & & $+n$ \\
\hline $\begin{array}{l}\text { b. Mischcultur des Staph. pyog. } \\
\text { alb. + Stäbchen }\end{array}$ & . & . & . & - & . & & . & . & & . & . & & + Wachsthum \\
\hline $\begin{array}{l}\text { V. Streptoc. pyog. in Form der Auf- } \\
\text { schwemmung }\end{array}$ & . & . & . & - & - & - & i. & & & ${ }^{\circ}$ & . & r & + typ. Wachsthum \\
\hline VI. Milzbrand in Form der Aufschw. & & & & & $\stackrel{+}{\mathrm{viel}} \mathrm{C}$ & $\stackrel{+}{\text { viel }} \mathrm{C}$ & $15 \stackrel{+}{\mathrm{Col}}$ & $\stackrel{+}{\mathrm{Co}}$ & $\stackrel{+}{\mathrm{Col}}$ & - & - & - & $+n$ \\
\hline
\end{tabular}


Wie die Abtödtung der Bacterien erfolgt, ist ohne weiteres nicht ersichtlich. Sehr bewegliche Stäbchen, wie der Vibrio Nordhafen, verlieren fast momentan ihre Beweglichkeit nach Berührung mit $\mathrm{H}_{2} \mathrm{O}_{2}$. Auch ist ein Unterschied in dem Färbeverhalten der Bacterien vor und nach Wasserstoffsuperoxydbehandlung nicht zu erkennen.

Zeigt so das $\mathrm{H}_{2} \mathrm{O}_{2}$ eine relativ hohe bactericide Eigenschaft - die etwa in die Mitte zwischen essigsaurer Thonerde und $1 \%$ Sublimatlösung zu setzen wäre -, so ist es auf der anderen Seite für das Leben der thierischen Gewebe absolut indifferent, abgesehen von intravenöser und subcutaner Injection und solcher in geschlossene Hohlräume, bei welcher Gelegenheit bei hinreichenden Dosen Tod durch Gasembolie eintreten kann. Alle Wunden dagegen und offenen Höhlen können damit berieselt werden, feuchte Verbände können tagelang liegen, ohne eine der lokalen oder toxischen Reizerscheinungen befürchten zu müssen, wie bei den gebräuchlichen Antisepticis. Unbeschadet kann es auf die Schleimhäute applicirt werden; Lebesque spülte die Bauchhöhle bei Peritonitis tuberculosa damit aus. Nur einmal ist mir ein geringes Ekzem des Unterarmes nach länger liegenden feuchten Verbänden vorgekommen, eine Erscheinung, die wohl nicht dem $\mathrm{H}_{2} \mathrm{O}_{2}$ als solchem, sondern vielmehr der feuchten Wärme zuzuschreiben ist und die man gelegentlich auch bei anderen feuchten Verbandarten beobachten kann.

Die Applicirung ist völlig schmerzlos. Oefters kommt es dagegen vor, dass man selbst ein intensiv prickelndes Gefühl in den Händen, bezw. Fingern hat, wenn dieselben durch vieles Waschen, Desinficiren etc. abgenützt sind.

Die Physiologie lehrt, ${ }^{2}$ ) dass das $\mathrm{H}_{2} \mathrm{O}_{2}$ durch die Berührung mit manchen thierischen Substanzen (Fibrin, rothe Blutkörperchen, Protoplasma) katalysirt, d. h. in Wasser und Sauerstoff gespalten wird, also eine Gasentwickelung stattfindet. Diese Gasentwickelung nun giebt den Anlass zu der zweiten empfehlenden Eigenschaft des $\mathrm{H}_{2} \mathrm{O}_{2}$ in der Wundbehandlung. Je mehr eine Wunde Gelegenheit zur Katalyse giebt, also ganz besonders eiternde und jauchende Prozesse mit ihrem zellreichen Sekret (Eiterkörperchen, Zellen, Bacterien etc.), um so stärker tritt die Gasentwickelung in Form einer Verschäumung in den Vordergrund, als deren Folge sich ein mechanisches Empor- und Losreissen fremder Elemente ergiebt, kurz - die Reinigung der Wunde.

Fast möchte es den Anschein haben, als ob bei dieser Frage auch der Bacteriengehalt der Sekrete eine Rolle spielt. Je bacterienreicher, um so schneller und lebhafter findet die Gasentwickelung statt, die in Form eines zähen Schaumes sich oft tagelang im Reagensglase hält. Besonders schön kann man dies beim Uebergiessen einer frischen Cultur sehen. Doch erlaube ich mir über diese Frage kein abschliessendes Urtheil.

Die Reinigung der Wunden ist in der That oft geradezu frappant. Eine Gangrän der Parotis, die mit einem zähen, schmierigen Belag bedeckt war, reinigte sich fast sofort nach einmaligem Uebergiessen mit $\mathrm{H}_{2} \mathrm{O}_{2}$; nekrotische Gewebsfetzen, die fest sassen und nur mit der Scheere hätten entfernt werden können, stossen sich spontan $a b$, so dass es nur des Zufassens der Pincette bedarf, um sie zu lösen. Nach 24 Stunden ist unter $\mathrm{H}_{2} \mathrm{O}_{2}$-Verband die handtellergrosse, bis auf den Kiefer reichende Wunde gereinigt, und frische Granulationen wachsen. Um nur einige Fälle herauszugreifen, so sahen wir einen ausgedehnten pyämischen Abscess, zwei schwere Phlegmonen, eine schwere Osteomyelitis in überraschend kurzer Zeit das Bild gesunder granulirender Wunden bieten.

Wenn man bedenkt, wie lange z. B. bei Osteomyelitis bisweilen die Eiterung trotz grösster Sorgfalt anhält, so ist es vielleicht von Interesse, dass in unserem Falle, der von einer "weisen Frau" vorbehandelt war, sich die scheusslich-schmierigen Wundverhältnisse binnen wenigèn Tagen reinigten, die Eiterung sistirte und unter kräftiger Granulationsentwickelung sich der Sequester zu markiren begann.

Die Desinficirung der Wunde geht daneben zum mindesten ebenso schnell vor sich wie bei $1 \%$ Sublimat- oder der schwachen essigsauren Thonerdelösung. Erkrankte und in ihren Lebensbedingungen schwer geschädigte Gewebspartieen, die sonst oft wochenlang Brut- und Culturstätten der Infection bilden, werden nebst Eiter und Bacterien abgestossen, frische Granula-

1) S. bei Thiriar.

2) Hermann, Lehrbuch der Physiologie. tionen beginnen zu wuchern - ein Bild, das man bei der Sublimat-, essigsauren Thonerde-, Alkohol- und trockenen Behandlung eiternder Prozesse nicht zu sehen gewöhnt ist. - Wir wenden jetzt bei inficirten Wunden das $\mathrm{H}_{2} \mathrm{O}_{2}$ stets an, sei es nun zur primären Desinfection und Reinigung der Wunde in Form der einfachen Aufgiessung oder nach Art des Falles auch zu feuchten Verbänden.

Eine dritte werthvolle Eigenschaft des $\mathrm{H}_{2} \mathrm{O}_{2}$ ist seine desodorisirende Kraft. Wenn man oft jauchende, inoperable Uteruscarcinome $\mathrm{zu}$ behandeln hat und Kalium permanganicum, Alkohol, Kohle, Naphthalin, Amylacetat etc. in Stich lassen, so empfindet man das Wasserstoffsuperoxyd als Erlösung. Ein zweimaliges Volllaufen- und Ausschäumenlassen der mit Specula auseinandergehaltenen Scheide genügt, um auch den hartnäckigsten Geruch wegzubringen, ohne dafür, wie z. B. bei der Verwendung des Amylacetats, einen anderen, auf die Dauer fast ebenso widerlichen zu setzen. Spült man nachher noch mit einer anderen indifferenten Lösung nach, um den Schaum $\mathrm{zu}$ entfernen, so findet man reine, geruchlose Wundverhältnisse vor. Ich glaube, diese eine angedeutete Verwendungsart bei stinkenden Prozessen wird genügen, einen Versuch damit zu rechtfertigen.

Das Wasserstoffsuperoxyd verdient mehr Verwendung in der Wundbehandlung zu finden als bisher. Es ist besonders für eiternde und jauchende Wundverhältnisse ein vorzügliches Mittel, das neben seiner beträchtlichen bactericiden Kraft in kürzester Zeit die Reinigung der Wunde bewirkt. Weiterhin findet die Desodorisirung der Wunde wie wohl kaum durch ein anderes Desodorans statt. Es ist absolut ungiftig, geruchlos, schmerzlos, von einer genügenden Haltbarkeit und von mässigem Preise. Andere Autoren fügen dieser grossen Reihe der Vorzüge noch die der blutstillenden Wirkung hinzu.

Meinem Chef, Herrn Dr. G. Middeldorpf, gestatte ich mir für seine Anregung und gütige Unterstützung meinen verbindlichsten Dank auszusprechen. 